\title{
On active anti-islanding techniques: survey
}

\author{
Y. A. Elshrief ${ }^{1}$, Sameh Abd-Elhaleem ${ }^{2}$, B. A. Abo Zalam ${ }^{3}$, A. D. Asham ${ }^{4}$ \\ ${ }^{1,4}$ Egyptian Academy for Engineering and Advanced Technology (EAE \& AT), Ministry of Military Production, Egypt \\ ${ }^{2,3}$ Faculty of Electronic Engineering, Menoufia University, Egypt
}

\begin{tabular}{ll}
\hline Article Info & ABSTRACT \\
\cline { 2 - 3 } Article history: & $\begin{array}{l}\text { The phenomenon of feeding loads from any distributed generators (DGs) } \\
\text { with a total disconnection of utility grid at the point of common coupling is } \\
\text { called islanding. The DGs are usually independently controlled. Hence, when } \\
\text { the islanding problem occurs, the electric utility loses the control and } \\
\text { Revised Mar 17, } 2021\end{array}$ \\
supervision over that section of the power grid. Furthermore, prolonged \\
islanding can prevent reconnection to the power grid and may cause damage \\
due to voltage and frequency excursions. Therefore, the islanding detection, \\
which is also called anti-islanding (AI), is one of the most critical aspects of \\
the integration of DG sources into the power grid. In this paper, a \\
comprehensive survey on the local AI techniques is illustrated, especially \\
active type which is used for improving the performance regarding the size \\
of the non-detection zone and detection speed. Extensive comparisons are \\
provided to demonstrate the effectiveness of each technique.
\end{tabular}

Photovoltaic

Power quality
This is an open access article under the CC BY-SA license.

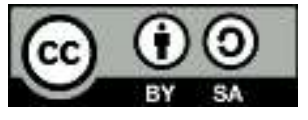

\section{Corresponding Author:}

Yasser Ahmed Elshrief

Department of Electrical Engineering

Egyptian Academy for Engineering and Advanced Technology (EAE \& AT)

Ministry of Military Production, Egypt

Email: yasserelshrief@yahoo.com

\section{INTRODUCTION}

Increasing the demand of energy over the world and in addition to the limited resources for traditional power generation methodologies, different distributed generators (DGs) resources such as wind turbines, solar energy, fuel cells, water turbines and micro-turbines, are utilized in modern distribution systems [1], [2]. As shown in Figure 1, the DG source at the end users generates a reverse power flow at the utility side which will affect the protection of utility. Nevertheless, sources of DG have been become increasingly popular because of its ability to solve several issues associated with conventional power systems [3]. The DG sources are distinguished by reduceing the demand on the transmission system, where the DGs are distributed near the load so, the reliability of the power grid is increased. Furthermore, the DGs have a lot of benefits such as reducing power losses, improving the voltage profile, enhancement of power quality (in some cases) [4].

On the other hand, some disadvantages affect the safety of the utility grid and the main dangerous problem is the islanding which is considered an undesirable phenomenon leads to power quality problems for the customer's loads, safety hazards for the humans which are working for maintenance the utility. In addition to, the islanding can cause a change in the fault level, frequency and voltage control problems, and power supply facilities as a result of unsynchronized recloser and damage to power generation [1]-[3]. Hence, according to the IEEE standards, this phenomenon should be detected within less than $2 \mathrm{~s}$.

As shown in Figure 2, the islanding phenomenon happens in conjunction with opening of the circuit breaker $(\mathrm{CB})$. The entire left side includes the generation and loads become isolated and the solar generation 
system continues to energize these isolated loads. This situation degrades the quality of power and creates an unsafe condition in the system.

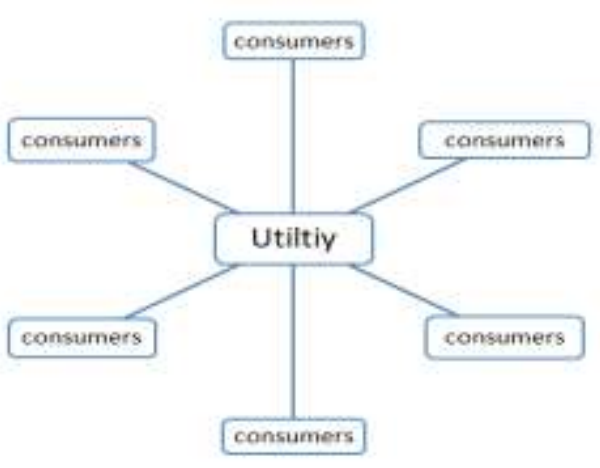

(a) Traditional distribution system

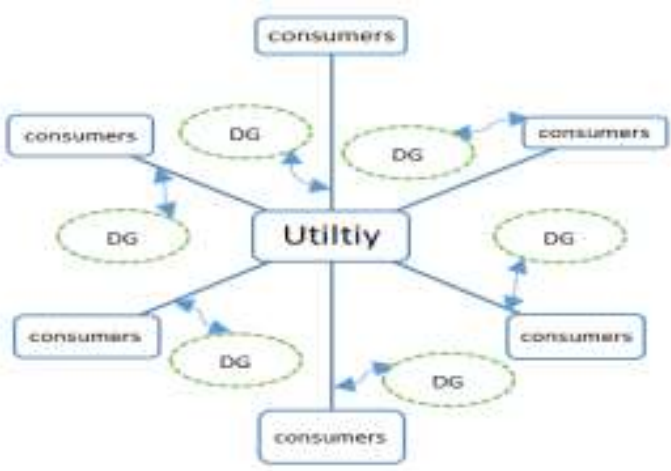

(b) Modern distribution system

Figure 1. Power distribution system (traditional and modern)

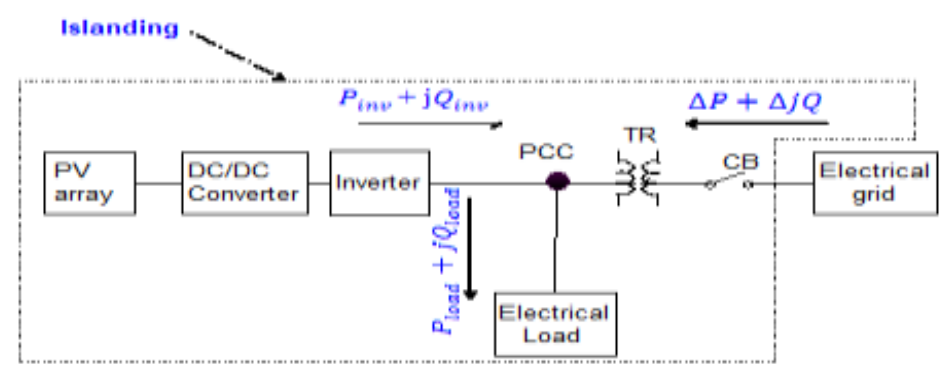

Figure 2. Model of a grid-disconnected DG source (islanding phenomenon)

There are two main techniques which are used for detecting islanding phenomenon, the remote and the local techniques, where the local technique is divided into passive and active as shown in Figure 3 . The basic idea of the remote techniques is illustrated as shown in Figure 4 by transmitting a low-energy signal continuously between the transmitter $(\mathrm{T})$ founded in the grid side and the receiver $(\mathrm{R})$ founded in the DG side. When this communication is failure, the receiver sends a stopping signal to the inverter and/or a switch (included in the receiver) should be opened for isolating the load from the DG [5].

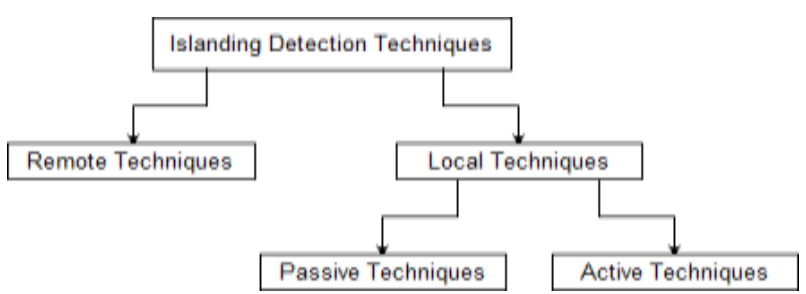

Figure 3. Classification of Islanding Techniques

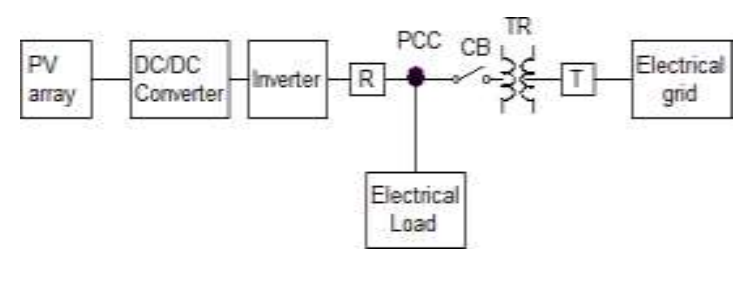

Figure 4. The general structure of the remote AI technique

The advantages of this technique are the output power quality of the inverter is not decreased, the ability of working in areas with high density of DG, it does not have non-detection zone (NDZ) and doesn't depend on the system size. Moreover, there some disadvantages such as the receiver and transmitter cost may be too high, it requires multiple signal generators and this has a high cost in comparison with a simple radial 
system, under abnormal conditions it has NDZ if some loads are operating. It needs a reliable communication system [5], [6] which requires enormous infrastructure and hence, extremely excessive cost. Consequently, these techniques are rarely used on a small scale.

This paper surveys the recently developed AI techniques applicable to inverter-based DG sources which are the largest and the fastest-growing sector [6]. The survey is organized as follows: The issue of islanding is discussed in Section two. Comparative AI techniques and the advantages and disadvantages for each technique especially the problem of NDZ and the impact of them on the power quality are presented in Section three. Finaly, the conclusion and an outlook for future research in this area is collected in Section four.

\section{ISSUES OF ISLANDING}

Intentional islanding is occurred by humans, who have authority on the system for maintenance or emergencies, but there is unintentional islanding that is happened without any interference from humans; both cases have many disadvantages as listed, a) safety issues arise for all humans who are working on the line, where they could have hazards as a result of the generated power from DG sources in case of the disconnection of power from a utility grid, b) the values of frequency and voltage may vary away from the standard permissible level, and c) unintentional reclosing may lead to a desynchronization of DG, which causes unexpected mechanical torque can destroy the generators [4].

Based on what has been put forward and the previous shortcomings, islanding must be detected quickly and accurately. To have the best AI method, two main aspects must be discussed, the NDZ and quality factor (Q factor) [7], [8]. The NDZ is defined by the interval which the islanding phenomenon is failed to be detected by traditional AI techniques [9]. As shown in Figure 5, the NDZ is the zone created in case of similarity between the local load consumed power and the DG generated power. In this case, both a reactive power variation $(\Delta \mathrm{Q})$ and a real power variation $(\Delta \mathrm{P})$ shown in Figure 6 , are zero. Thus, the utility grid does not supply any power and hence, the disconnection of utility could not be detected, even with using over/ under frequency $(\mathrm{OF}, \mathrm{UF})$ and voltage $(\mathrm{OV}, \mathrm{UV})$ relays.

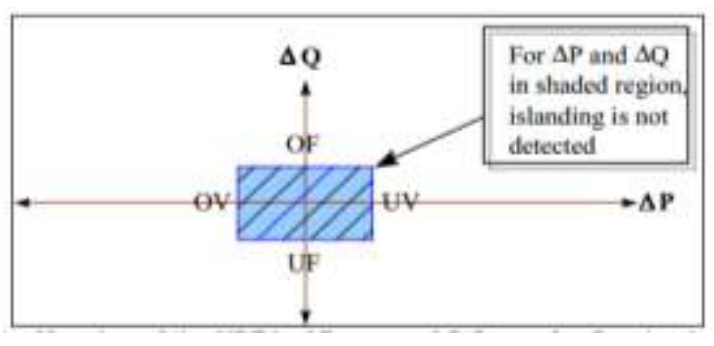

Figure 5. NDZ in $\Delta P$ versus $\Delta Q$ for over/under frequency and voltage

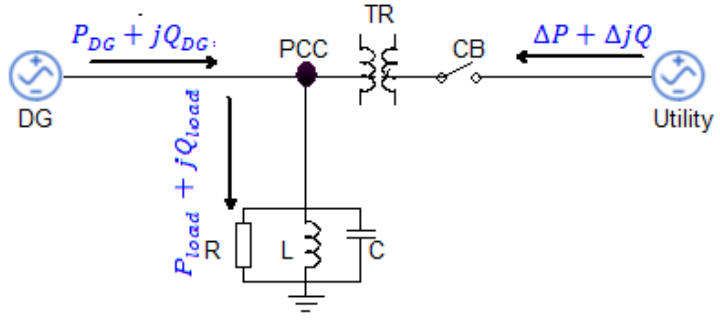

Figure 6. RLC load between DG and utility

Therefore, the NDZ is regarded as the main parameter for detecting islanding. The other aspect is the quality factor $Q_{f}$ in (1) for any known frequency defined as the ratio of maximum stored energy over energy consumed per cycle times multiplied by two [10]. The $Q_{f}$ factor can be used to represent the relationship between stored energy and the dissipated one in the RLC load, which located between DG and utility Grid. As shown in Figure 6 , the single line diagram of a grid is connected to the DG source. The real power $(\Delta \mathrm{P})$ and reactive power $(\Delta \mathrm{Q})$ are delivered. The $P_{D G}$ and $Q_{D G}$ are the real and reactive power delivered by the DG source respectively. Similarly, the $P_{\text {load }}$ and $Q_{\text {load }}$ are the real and reactive power absorbed by the load, and its values are affected by the potential of local loads within the isolated part of the system.

$$
\text { Quality factor }\left(Q_{f}\right)=2 * \frac{\text { Energy stored }}{\text { Energy consumed per cycle }}
$$

In particular, a lot of AI methods suffer from NDZ especially the passive one. However, the smaller NDZ is preferred [6]. The relation between the $Q_{f}$ factor and NDZ is proportional, that means, any decreasing of the NDZ will improve the time response of islanding detection, but it will lead to a decrement in $Q_{f}$ factor. Obtaining the best results for all parameters becomes the core of the research area nowadays. 


\section{AI TECHNIQUES}

To resolve the problem of islanding, the AI techniques which are categorized to remote and local will be used [6]. Under these two categories, a lot of control techniques are provided depending on the method of detection for each one. As shown in Figure 7, the operation of local AI techniques is classified into passive and active techniques. Passive methods depend on monitoring several parameters such as frequency, current and voltage. Then setting thresholds for these parameters can help for islanding detection if the value of any parameter is out of range. The implementation of this technique is fast, easy, more uncomplicated and has no disturbance in the system, despite all these advantages, it has a significant NDZ [11] which is considered the primary defect in this technique even we use traditional passive techniques or smart techniques [12]-[18].

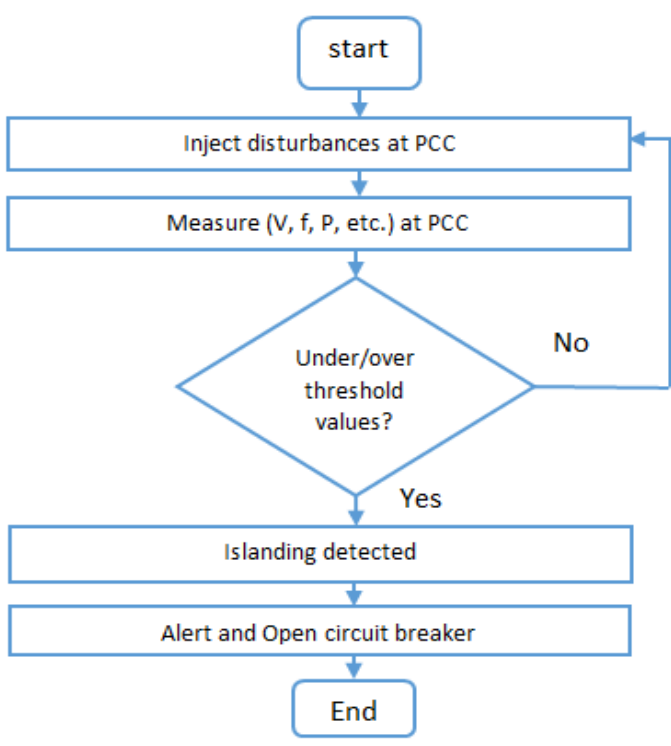

(a) Active techniques

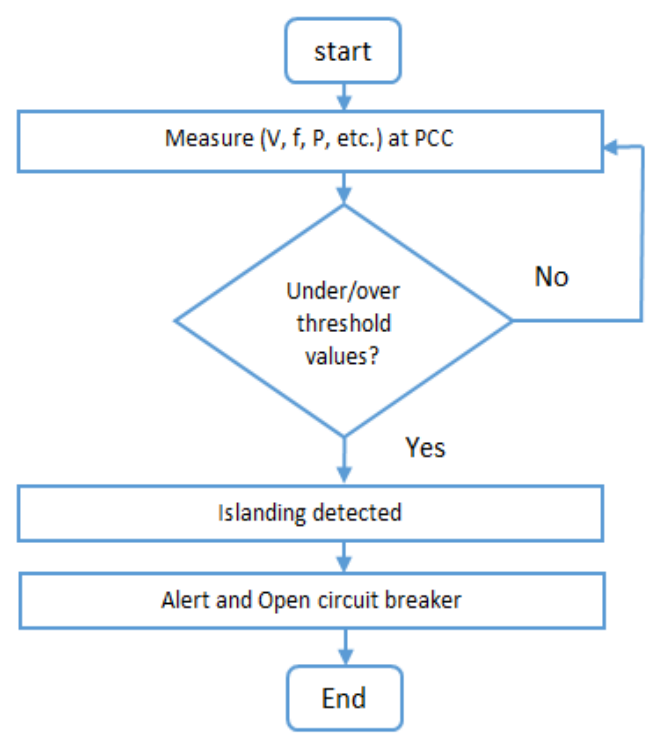

(b) Passive techniques

Figure 7. Flow chart of local AI Techniques (a) passive (b) active

The challenge of the passive methods is how to select the convenient threshold [19] which is matched with the IEEE 1547 standard. Table 1 summurizes this standard in order to sure that the islanding has happened or there is another disturbance affects the system. The mechanism of detecting islanding for passive techniques is shown in Figure 7 (b). This paper will be focused on active AI techniques and discussed in detail in the following subsection.

Table 1. Standard IEEE 1547 for AI Techniques

\begin{tabular}{ll}
\hline Parameters & Standard \\
\hline Range of Voltage & $88 \% \leq \mathrm{V} \leq 110 \%$ \\
Range of Frequency & $49 \mathrm{HZ} \leq \mathrm{f} \leq 50 \mathrm{HZ}$ \\
Maximum time for islanding detection & 2 second \\
Total Harmonic Distortion (THD $\%)$ & $\leq 5 \%$ \\
\hline
\end{tabular}

Active methods introduce intentional disturbances to the rest of the circuit and then analyze the feedback to decide whether there is an islanding or not [20]. The mechanism of detecting islanding for Active techniques is shown in Figure 7 (a).

Despite, the active methods have small NDZ, but unfortunately it leads to decreasing power quality of thesystem. In addition to, these methods may change the magnitude of the output for the inverter either frequency or current. Although, there are some active methods can detect islanding without decreasing power quality, it will require using many controllers that will increase the complexity for the implementation and more expensive than the other local techniques [21]-[41]. AI detection techniques are explained in detail in the rest of this subsection. 
a. Active frequency drift (AFD) technique

In this techniue, some disturbances of the current signal are injected into the point of common coupling (PCC) depending on $V_{P C C}$ which follows the fundamentals of $I_{\text {inv }}$, where $V_{P C C}$ and $I_{\text {inv }}$ represent the PCC voltage and inverter output current respectively. Hence, in the grid-connected mode, this distortion does not affect the current and voltage. Therefor, the frequency of the system has the same frequency of the grid. In the other hand, the grid-disconnected mode (islanding condition) has distortion leads to a phase difference between the current and voltage. Hence, this difference leads to a drift in frequency that obligates the UF/OF relays to cutoff the DG from the rest of the circuit. As shown in Figure 8, it is a comparison between a waveform of distorted DG output current with undistorted sine waveform. The chopping factor $C_{f}$ is used to calculate the intensity of the disturbance as in the (2).

$$
C_{f}=\frac{2 t_{z}}{T}
$$

Where, $T$ is the voltage period of the grid and $t_{z}$ is the dead time. However, this technique can easily be implemented using a microprocessor. It affects the power quality [42]-[53].

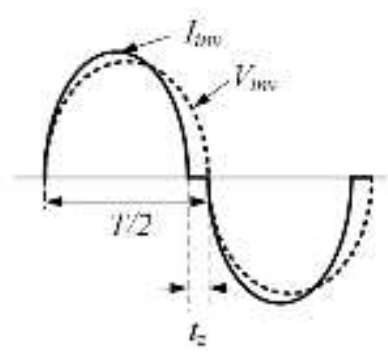

Figure 8. Waveform of AFD Technique [48]

b. Slip-mode frequency shift (SMS) technique

In this Technique, SMS is based on a positive feedback destabilization for the output of the inverter in order to detect islanding state which changes relative to the grid voltage. In grid disconnection mode, it will obligate the frequency of the voltage at PCC to deviate from the standard value. In contrast to the other active methods, SMS is characterized by a limited NDZ and assumed as an efficient method for AI detection. In contrast with the other methods that depend on positive feedback, SMS has some drawbacks such as perturbation in the phase shift which can cause noise, quantization error and, measurement error. By using extra phase shift known as the improved slip mode frequency shift (IM-SMS) to overcome all drawbacks of SMS, besides easy implemenationt, simpler and more reliable [54].

c. Impedance measurement technique

This technique is classified as similar to a passive technique. It monitors the variations of the system impedance which occur by islanding. Furthermore, this technique will lead to a reduction in voltage and current as a result of temporarily parallel connected inductor across the utility grid, but it nearly has not NDZ, especially in the single-inverter case [55].

In grid-connected mode, in case of a large difference between the harmonic frequency impedance of the DG and the load, as shown in Figure 9 (a), the equivalent impedance will be smaller due to the existence of low grid impedance $Z_{\text {Grid }}$ that is parallelly connected with the load impedance $Z_{\text {Load }}$ as shown in (3). However, in the case of islanding mode, there is only one way to flow, so any difference can force the under/over voltage protection relays to work and stop the inverter's operation as.

$$
Z_{\text {Equivelant }}=\left\{\begin{array}{cc}
Z_{\text {Load }} \| Z_{\text {Grid }} & \text { if grid connected } \\
Z_{\text {Load }} & \text { if islanding }
\end{array}\right.
$$

These experimental studies prove that the method of impedance measurement used for detecting islanding may have small NDZ in the single-inverter cases, but the main disadvantage appears in parallel multiple inverters cases, as each one forces a slightly different signal into the line [56]. Adding a variable length in phase shift will lead to an increase in the accuracy for the single-inverter case, but unfortunately, this enhancement will add a few numbers of harmonics on the output of the inverter. Hence, other AI methods are used to solve the drawbacks of impedance measurement techniques. 


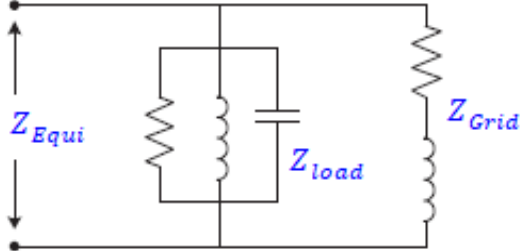

(a) Mode of grid connection

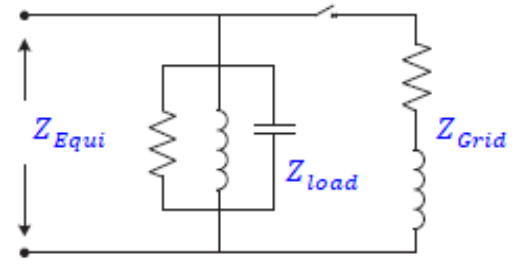

(b) Mode of grid disconnection

Figure 9. Equivalent impedance within grid connection and disconnection mode

\section{d. Sandia frequency shift (SFS) technique}

The SFS technique is known as a modified active frequency drift (AFD) technique which depends on a feedback by injecting a small phase shift at the output current of the inverter. So, there is a deviation between the inverter output current and power system frequencies. The (4) shows the chopping factor that is proportionally related to the difference between the utility and inverter frequency.

$$
C_{f}=C_{f 0}+\mathrm{K}\left(f_{0}-\mathrm{f}\right)
$$

Where $C_{f 0}$ is the chopping factor at zero frequency error, $\mathrm{K}$ is the accelerating gain, and $f_{0}$ and,$f$ are the PCC measured frequency and line one, respectively. The $C_{f}$ becomes low in case of that the frequency error equals zero as the utility stabilizes the voltage at PCC through a reference for phase and frequency. In the case of grid connection mode, a small variation in frequency but has a negligible effect. However, in the case of islanding mode, PCC frequency increases then the frequency error increases, which in turn raises the frequency of the inverter. The process will persist until happening the matching for the limits of threshold and islanding is detected.

Although SFS has a reduced NDZ and is the most convenient among the other active methods, it reduces the output power quality of the inverter. Moreover, it introduces noise and harmonics [57]. So, detecting the islanding phenomenon has done in this case by the under/over frequency protection relays and take action to stop the inverter's operation [57]-[63].

e. Sandia voltage shift (SVS) technique

In this technique, the SVS used for preventing the islanding based on the method of positive feedback, which mainly depends on the PCC's voltage amplitude. In the case of grid-connected mode, there is no effect on the power system, but when disconnection occurs between the utility grid and DG, it will lead to a reduction in PCC voltage. So, detecting islanding phenomenon, in this case, can be done by using the under/over voltage protection relays and take action to stop the inverter's operation [64]. This Technique has a smaller NDZ than the other techniques in addition to a fast detection speed if the convenient accelerating factor is chosen.

The recapitulation of the various local islanding detection methods (IDMs) and a comparison between passive and active techniques with respecting to its classification, concept, detection time, cost which affect on the power quality and the size of NDZ. In these cases, detection of islanding will be presented as shown in Table 2 as it characterizes the various IDMs in terms of their merits, demerits, and other performance capabilities. Hence, from Table 2, the SFS method is the fastest method for detecting islanding according to [61] but unfortunately, this method leads to a current distortion.

\section{CONCLUSION}

This paper presented a comprehensive review for several updated active islanding detection techniques during the connection between the utility grid and PV systems. Based on the whole discussion and trends at this point, local AI methods are classified into passive and active. The passive method depends on displaying some parameters of the system as frequency and voltage. But the active technique depends on injecting some perturbations on the output current or voltage of the inverter. Hence, this paper focused on the active techniques. According to the detailed comparison between active methods, it can be noticed that these methods are featured by small power degradations, faster response, high reliability and can decrease NDZ. But these techniques are not easy for implementation as the passive ones. Passive methods do not affect output power quality and simple to implement but have large NDZ. So, it is recommended to use a hybrid 
technique that incorporates local techniques and artificial intelligence to have accurate islanding detection under various load conditions, which is predicted to be faster than all other methods and achieves the standard time according to IEEE 1547.

\section{APPENDIX}

Table 2. A comparison of local islanding detection methods

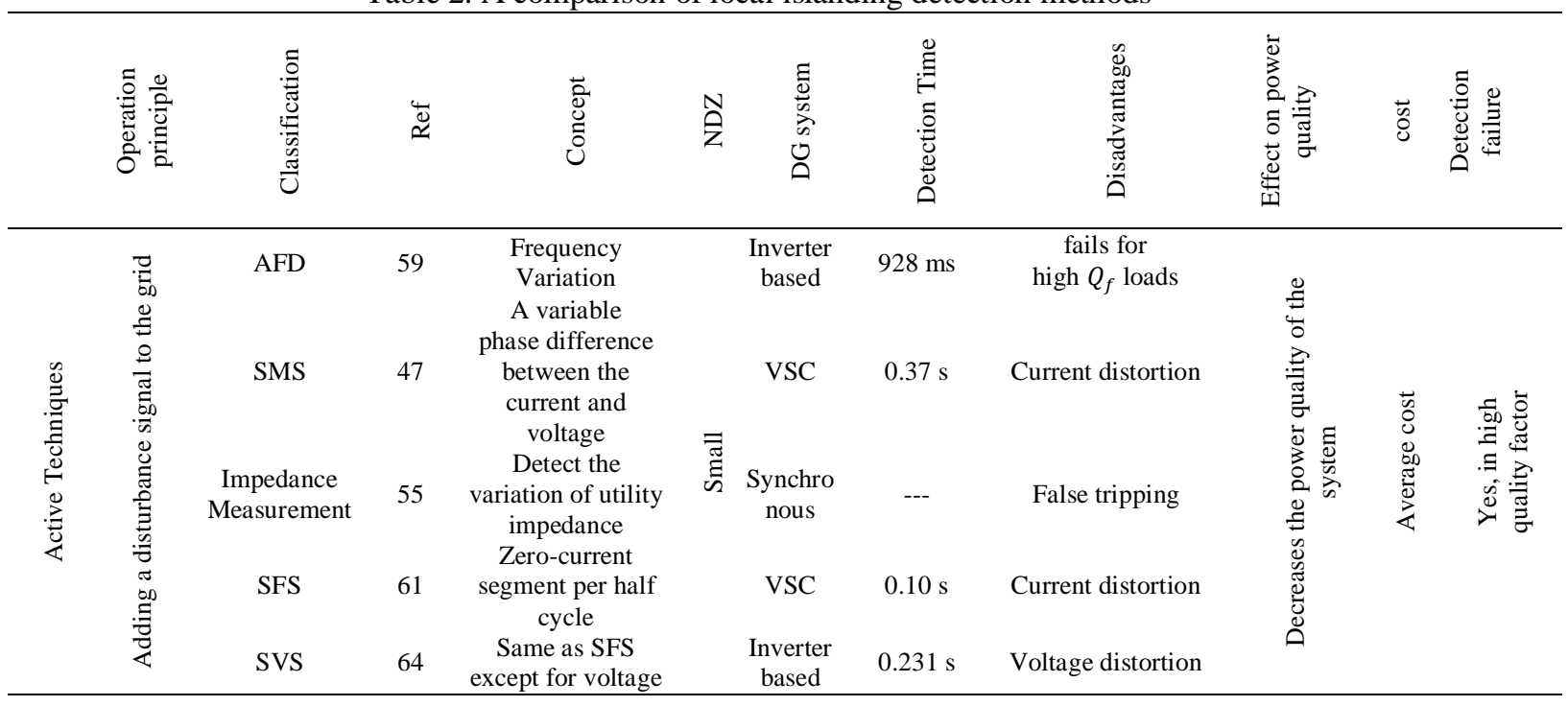

\section{REFERENCES}

[1] V.E.Santos, A.G.Martins and C.H.Antunes, "A multi-objective model for sizing and placement of distributed generation," Proceedings of the 6th WSEAS International Conference on Power Systems, Lisbon, Portugal, September 22-24, 2006.

[2] Ch. Rami Reddy, and K. Harinadha Reddy, "A passive islanding detection method for neutral point clamped multilevel inverter based distributed generation using rate of change of frequency analysis," International Journal of Electrical and Computer Engineering (IJECE), vol. 8, no. 4, pp. 1967-1976, 2018, doi: 10.11591/ijece.v8i4.pp1967-1976.

[3] Y. A. Elshrief, D. H. Helmi, A. D. Asham and B. A. Abozalam, "Merits and demerits of the distributed generations connected to the utility grid," Menoufia Journal of Electronic Engineering Research, vol. 28, no. 1, pp. 259-262 2019, doi: 10.21608/mjeer.2019.70907.

[4] T. Zheng, H. Yang, R. Zhao, Y. Kang and V. Terzija, "Design, evaluation and implementation of an islanding detection method for a micro-grid," Energies, vol. 11, no. 2, pp. 323, 2018, doi: 10.3390/en11020323.

[5] Y. A. Elshrief, A. D. Asham, D. H. Helmi, and B. A. Abozalam, "On remote anti-islanding detection techniques," The Future of Electricity Challenges Aoand Opportunities, 2019, pp. 297-304.

[6] M. Bakhshi, R. Noroozian and G.B. Gharehpetian, "Anti-islanding scheme for synchronous DG units based on Tufts-Kumaresan signal estimation method," IEEE Transactions on Power Delivery, vol. 28, no. 4, pp. 2185-2193, 2013, doi: 10.1109/TPWRD.2013.2271837.

[7] Y.A. Elshrief, S. Abd-Elhaleem, A.D. Asham, and B.A. Abozalam, "AI protection algorithms for PV-grid connection system," International Conference on Innovative Trends in Communication and Computer Engineering (ITCE), pp. 334-341, 2020, doi: 10.1109/ITCE48509.2020.9047774.

[8] Z. Ye, A. Kolwalkar, Y. Zhang, P. Du and R. Walling, "Evaluation of anti-islanding schemes based on nondetection zone concept," IEEE Transactions on Power Electronics, vol. 19, no. 5, pp. 1171-1176, 2004, doi: 10.1109/TPEL.2004.833436.

[9] W. Xu, K. Mauch and S. Martel, "An assessment of distributed generation islanding detection methods and issues for Canada," CANMET Energy Technology Centre-Varennes, Natural Resources Canada, QC-Canada, Tech. Rep. CETC-Varennes, 2004.

[10] Masoud Ahmadipour, Hashim Hizam, Mohammad Lutfi Othman, Mohd Amran Mohd Radzi, and Nikta Chireh, "A novel islanding detection technique using modified Slantlet transform in multi-distributed generation," International Journal of Electrical Power \& Energy Systems, vol. 112, no.1, pp. 460-475, 2019, doi: 10.1016/j.ijepes.2019.05.008.

[11] B. Guha, R.J. Haddad and Y. Kalaani, "A passive islanding detection approach for inverter-based distributed generation using rate of change of frequency analysis," Southeast Con 2015, IEEE., 2015, doi: 10.1109/ICPEICES.2016.7853720. 
[12] Y. A. Elshrief, A. D. Asham, D. H. Helmi, and B. A. Abozalam, "ROCOF for detecting Islanding of Photovoltaic system," Menoufia Journal of Electronic Engineering Research, vol. 28, ICEEM2019-Special Issue, pp.225-258, 2019, doi: 10.21608/mjeer.2019.70897.

[13] Y.A. Elshrief, G.A. Atlam, and B.A. Abozalam, "Adaptive-fuzzy logic power filter for nonlinear systems," IOSR Journal of Electrical and Electronics Engineering (IOSR-JEEE), vol. 11, no. 2, pp. 66-73, 2016, doi: 10.9790/1676-1102016673.

[14] Y.A. Elshrief, G.A. Atlam, and B.A. Abozalam, "Adaptive hysteresis active power filter using fuzzy-logic controller for nonlinear systems," Menoufia Journal of Electronic Engineering Research, vol. 26, no. 1, pp. 99-112, 2017, doi: 10.21608/mjeer.2017.63429.

[15] Y.A. Elshrief, H.F. Elakbawy, G.A. Atlam, and B.A. Abozalam, "Comparison between the fixed_band HCC and adaptive HCC used for APF control," IOSR Journal of Electrical and Electronics Engineering (IOSR-JEEE), vol. 11, no. 3, pp. 54-59, 2016, doi: 10.9790/1676-1103045459.

[16] B. Anudeep and P.K. Nayak, "A passive islanding detection technique for distributed generations," 2017 th International Conference on Power Systems (ICPS), 2017, doi: 10.1109/ICPES.2017.8387386.

[17] Y.A. Elshrief, S. Abd-Elhaleem, B.A. Abozalam, and A.D. Asham, "Methods for protecting network from islanding danger," Authorea, January 25, 2021.

[18] A.S. Aljankawey, W.G. Morsi, L. Chang and C.P. Diduch, "Passive method-based islanding detection of renewable-based distributed generation: the issues," 2010 IEEE Electrical Power \& Energy Conference IEEE, 2010, doi: 10.1109/EPEC.2010.5697253.

[19] Ramireddy Chilakala, K Suresh, P Anusha, Sk Najma, B. I. Rajkumar, and B. Prasanna Lakshmi, "A passive islanding detection method for hybrid distributed generation system under balanced islanding," Indonesian Journal of Electrical Engineering and Computer Science (IJEEECS), vol. 1, no. 1, pp. 9-19, 2019, doi: 10.11591/ijeecs.v14.i1.pp9-19.

[20] P.V. Brennan, Phase-locked loops: principles and practice, Macmillan International Higher Education, 1996.

[21] M.S. Kim, R. Haider, G.J. Cho, C.H. Kim, C.Y. Won and J.S. Chai, "Comprehensive review of islanding detection methods for distributed generation systems," Energies, vol. 12, no. 5, p. 837, 2019, doi: 10.3390/en12050837.

[22] W. Bower and M. Ropp, Evaluation of islanding detection methods for utility-interactive inverters in photovoltaic systems, Sandia report SAND, pp. 2002-3591, 2002.

[23] B. Singam and L. Hui, "Assessing SMS and PJD schemes of anti-islanding with varying quality factor," 2006 IEEE International Power and Energy Conference, 2006, doi: 10.1109/PECON.2006.346645.

[24] Reza Zamani, Mohammad Esmail Hamedani Golshan, Hassan Haes Alhelou, and Nikos Hatziargyriou, "A novel hybrid islanding detection method using dynamic characteristics of synchronous generator and signal processing technique," Electric Power Systems Research, vol. 175, pp. 105-119, 2019, doi: 10.1016/j.epsr.2019.105911.

[25] A. Llaria, O. Curea, J. Jime'nez and H. Camblong, "Survey on microgrids: unplanned islanding and related inverter control techniques," Renewable energy, vol. 36, no. 8, pp. 2052-2061, 2011, doi: 10.1016/j.renene.2011.01.010.

[26] W. Xu, G. Zhang, C. Li, W. Wang, G. Wang and J. Kliber, "A power line signaling based technique for antiislanding protection of distributed generators-Part I: Scheme and analysis," IEEE Transactions on Power Delivery, vol. 22, no. 3, pp. 1758-1766, 2007, doi: 10.1109/TPWRD.2007.899618.

[27] P. Mahat, Z. Chen and B. Bak-Jensen, "Review of islanding detection methods for distributed generation," 2008 Third International Conference on Electric Utility Deregulation and Restructuring and Power Technologies, 2008, doi: 10.1109/DRPT.2008.4523877.

[28] P. Mahat, Z. Chen and B. Bak-Jensen, "Review on islanding operation of distribution system with distributed generation," 2011 IEEE Power and Energy Society General Meeting IEEE, 2011, doi: 10.1109/PES.2011.6039299.

[29] A. Khamis, H. Shareef, E. Bizkevelci and T. Khatib, "A review of islanding detection techniques for renewable distributed generation systems," Renewable and sustainable energy reviews, vol. 28,no.1, pp. 483-493, 2013, doi: 10.1016/j.rser.2013.08.025.

[30] A. Samui and S.R. Samantaray, "Assessment of ROCPAD relay for islanding detection in distributed generation," IEEE Transactions on Smart Grid, vol. 2, no. 2, pp. 391-398, 2011, doi: 10.1109/TSG.2011.2125804.

[31] M. Vatani, T. Amrall and I. Soltan, "Comparative of islanding detection passive methods for distributed generation application," International Journal of innovation \& Scientific Research, vol. 8, no. 2, pp. 234-241, 2014.

[32] E.O. Schweitzer, D. Whitehead, G. Zweigle, K.G. Ravikumar, and Greg Rzepka, "Synchrophasor-based power system protection and control applications," International Symposium Modern Electric Power Systems (MEPS) Wroclaw, Poland September 20-22, 2010.

[33] R. Nale and M. Biswal, "Comparative assessment of passive islanding detection techniques for microgrid," 2017 International Conference on Innovations in Information, Embedded and Communication Systems (ICIIECS), 2017, doi: 10.1109/ICIIECS.2017.8275935.

[34] C.S. Chandrakar, B. Dewani and D. Chandrakar, "An assessment of distributed generation islanding detection methods," International Journal of Advances in Engineering \& Technology, vol. 5, no. 1, pp. 205-218, 2012.

[35] J. Rajesh Reddy, and A. Pandian, "Improved ROCOF relay for islanding detection of solar distributed generation," Indonesian Journal of Electrical Engineering and Computer Science, vol. 14, no. 3, pp. 1105-1113, 2019, doi: 10.11591/ijeecs.v14.i3.pp1105-1113.

[36] M. Ropp, D. Larson, S. Meendering, D. Mc Mahon, J. Ginn, J. Stevens, et al., "Discussion of a power line carrier communications-based anti-islanding scheme using a commercial automatic meter reading system," 2006 IEEE 4th World Conference on Photovoltaic Energy Conference IEEE, 2006, doi: 10.1109/WCPEC.2006.279663. 
[37] B. Yu, M. Matsui, A.G. Abo-Khalil and G.Yu, "A correlation-based islanding detection method using current disturbance for PV system," Proceedings of the International Conference on Electrical Machines and Systems ICEMS, Tokyo, Japan, 2009.

[38] P. Gupta, R.S. Bhatia and D.K. Jain, and Ruchika, "Active islanding detection technique for distributed generation," INAE Letters, vol. 3, no. 6, pp. 243-250, 2018, doi: 10.1007/s41403-018-0054-z.

[39] G. Hernandez-Gonzalez and R. Iravani, "Current injection for active islanding detection of electronically-interfaced distributed resources," IEEE Transactions on power delivery, vol. 21, no. 3, pp. 1698-1705, 2006, doi: 10.1109/TPWRD.2006.876980.

[40] F. Mango, M. Liserre and A. Dell'Aquila, "Overview of anti-islanding algorithms for pv systems, part ii: activemethods," 2006 12th International Power Electronics and Motion Control Conference IEEE, 2006, doi: 10.1109/EPEPEMC.2006.4778680.

[41] Z. Chunjiang, L. Wei, S. Guocheng and W. Weiyang, "A novel active islanding detection method of grid-connected photovoltaic inverters based on current-disturbing," 2006 CES/IEEE 5th International Power Electronics and Motion Control Conference IEEE, 2006, doi: 10.1109/IPEMC.2006.4778243.

[42] H. Karimi, A. Yazdani and R. Iravani, "Negative-sequence current injection for fast islanding detection of a distributed resource unit," IEEE Transactions on Power Electronics, vol. 23, no. 1, pp. 298-307, 2008, doi: 10.1109/TPEL.2007.911774.

[43] B. Wen, D. Boroyevich, R. Burgos, Z. Shen and P. Mattavelli, "Impedance-based analysis of active frequency drift islanding detection for grid-tied inverter system," IEEE Transactions on industry applications, vol. 52, no. 1, pp. 332-341, 2015, doi: 10.1109/TIA.2015.2480847.

[44] J.H. Kim, J.G. Kim, Y.H. Ji, Y.C. Jung and C.Y. Won, "An islanding detection method for a grid-connected system based on the goertzel algorithm," IEEE Transactions on Power Electronics, vol. 26, no. 4, pp. 1049-1055, 2011, doi: 10.1109/TPEL.2011.2107751.

[45] H. Li, Z. Li, Z. Guo and J. Lu, "A novel unscheduled islanding detection method for microgrid," International Conference on Electrical Engineering, Control and Robotics, vol. 160, pp. 1-5, 2018, doi: 10.1051/matecconf/201816004001.

[46] N. Boonyapakdee, T. Sapaklom and M. Konghirun, "An implementation of improved combine active islanding detection method based on frequency and phase perturbations," 2013 International Conference on Electrical Machines and Systems (ICEMS) IEEE, 2013, doi: 10.1109/ICEMS.2013.6754433.

[47] F. Liu, Y. Kang, Y. Zhang, S. Duan and X. Lin, "Improved SMS islanding detection method for grid-connected converters," IET Renewable Power Generation, vol. 4, no. 1, pp. 36-42, 2010, doi: 10.1049/iet-rpg.2009.0019.

[48] A.Y. Hatata, El-H. Abd-Raboh and Bishoy E. Sedhom, "Proposed sandia frequency shift for anti-islanding detection method based on artificial immune system," Alexandria Engineering Journal, vol. 57, no. 1, pp. 235-245, 2018, doi: 10.1016/j.aej.2016.12.020.

[49] M. El-Moubarak, M. Hassan and A. Faza, "Performance of three islanding detection methods for grid-tied multiinverters," 2015 IEEE 15th International Conference on Environment and Electrical Engineering (EEEIC) IEEE, 2015, doi: 10.1109/EEEIC.2015.7165481.

[50] M.E. Ropp, M. Begovic, and A. Rohatgi, "Prevention of islanding in grid-connected photovoltaic systems," Progress in Photovoltaics: Research and Applications, vol. 7 no. 1, pp. 39-59, 1999, doi: 10.1002/(SICI)1099159X(199901/02)7:1<39::AID-PIP246>3.0.CO;2-J.

[51] L.P. Raghav and T. Sandhya, "An active frequency drift method for an islanding detection of grid connected micro turbine generation system," Int. J. Innovat. Res. Sci. Eng. Technol.-(ICETS'14), vol. 3, no. 1, 2014.

[52] A. Yafaoui, B. Wu and S. Kouro, "Improved active frequency drift anti-islanding method with lower total harmonic distortion," IECON 2010-36th Annual Conference on IEEE Industrial Electronics Society IEEE, 2010, doi: 10.1109/IECON.2010.5675051.

[53] W. Huang, T. Zheng, F. Yuan, Z. Wang, S. Xu, X. Wang, et al., "Analysis of the NDZ formulation theory of active frequency shift islanding detection method for grid-connected PV system," 2013 IEEE PES Asia-Pacific Power and Energy Engineering Conference (APPEEC), 2013, doi: 10.1109/APPEEC.2013.6837277.

[54] J. Merino, P. Mendoza-Araya, G. Venkataramanan and M. Baysal, "Islanding detection in microgrids using harmonic signatures," IEEE Transactions on Power Delivery, vol. 30, no. 5, pp. 2102-2109, 2014, doi: 10.1109/TPWRD.2014.2383412.

[55] S. Dutta, P.K. Sadhu, M.J.B. Reddy and D. KMohanta, "Shifting of research trends in islanding detection method-a comprehensive survey," Protection and Control of Modern Power Systems, vol. 1, no. 1, pp. 3-23, 2018.

[56] M. Ropp, J.,Ginn, J.,Stevens, W.,Bower and S. Gonzalez, "Simulation and experimental study of the impedance detection anti-islanding method in the single-inverter case," 2006 IEEE 4th World Conference on Photovoltaic Energy Conference, 2006, doi: 10.1109/WCPEC.2006.279670.

[57] C.H. Yoo, D.H. Jang, S.K. Han, D.S. Oh and S.S. Hong, "A new phase drift anti-islanding method for gridconnected inverter system," 8th International Conference on Power Electronics-ECCE Asia, 2011, doi: 10.1109/ICPE.2011.5944637.

[58] W.Y. Teoh and C.W. Tan, "An overview of islanding detection methods in photovoltaic systems," World Academy of Science, Engineering and Technology, vol. 58, no. 10, pp. 674-682, 2011, doi: 10.5281/zenodo.1061625.

[59] H.H. Zeineldin and S. Conti, "Sandia frequency shift parameter selection for multi-inverter systems to eliminate non-detection zone," IET Renewable Power Generation, vol. 5, no. 2, pp. 175-183, 2011, doi: 10.1049/ietrpg.2010.0096. 
[60] H. Vahedi and M. Karrari, "Adaptive fuzzy sandia frequency-shift method for islanding protection of inverterbased distributed generation," IEEE Transactions on Power Delivery, vol. 28, no. 1, pp. 84-92, 2012, doi: 10.1109/TPWRD.2012.2219628.

[61] L.A.C. Lopes and H. Sun, "Performance assessment of active frequency drifting islanding detection methods," IEEE Transactions on Energy Conversion, vol. 21, no. 1, 2006, pp. 171-180, doi: 10.1109/TEC.2005.859981.

[62] X. Wang, W. Freitas and W. Xu, "Dynamic non-detection zones of positive feedback anti-islanding methods for inverter-based distributed generators," IEEE Transactions on Power Delivery, vol. 26, no. 2, pp. 1145-1155, 2011, doi: 10.1109/TPWRD.2010.2090672.

[63] A. Abokhalil, A. Awan and A.R. Al-Qawasmi, "Comparative study of passive and active islanding detection methods for PV grid-connected systems," Sustainability, vol. 10, no. 6, pp. 1798-1813, 2018, doi: $10.3390 /$ su10061798.

[64] C.L. Trujillo, D. Velasco, E. Figueres, and G. Garcerá, "Analysis of active islanding detection methods for gridconnected microinverters for renewable energy processing," Applied Energy, vol. 87, no. 11, pp. 3591-3605, 2010, doi: 10.1016/j.apenergy.2010.05.014.

\section{BIOGRAPHIES OF AUTHORS}

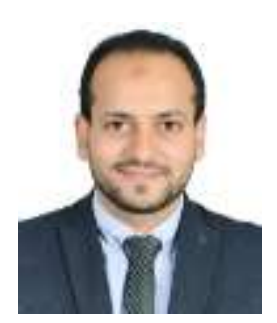

Yasser Elshrief received the B.Sc., and M.Sc. degrees in Electronic Engineering from the Faculty of Electronic Engineering, Menoufia University in 2010, 2016 respectively. He is currently pursuing the Ph.D. degree in renewable energy systems, from Menoufia University. $\mathrm{He}$ is currently an Assistant Lecturer with the Electrical Department at the Egyptian Academy for Engineering and Advanced Technology (EAE \& AT), affiliated to the Ministry of Military Production. His current research interests include intelligent control systems, renewable energy systems and nonlinear control.

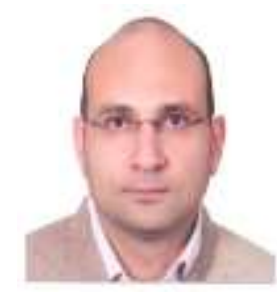

Amin Danial has got his Bachelor, M.Sc. and Ph.D. degrees from the faculty of Engineering Cairo university in 1994, 2002, 2009 respectively. He is currently, the head of the mechatronics Department at the Egyptian Academy for Engineering and Advanced Technology (EAE \& AT), affiliated to the Ministry of Military Production. His current research interests include intelligent control systems, renewable energy systems and nonlinear control.

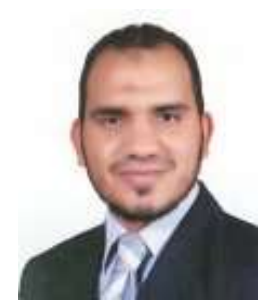

Sameh Abd-Elhaleem received the B.Sc., M.Sc., and Ph.D. degrees in automatic control engineering from Menoufia University, Shibin Al Kawm, Egypt, in 2005, 2012, and 2018, respectively. He is currently a Lecturer with the Department of Industrial Electronics and Control Engineering, Faculty of Electronic Engineering, Menoufia University. His current research interests include intelligent control systems, robust control, networked control systems, optimization algorithms, renewable energy systems and nonlinear control.

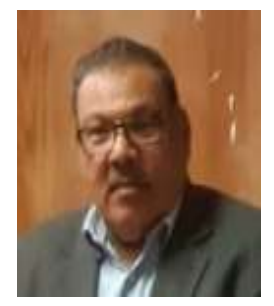

Belal Abo Zalam graduated from Menoufia University, Faculty of Electronic Engineering, Egypt in 1975. He received the M.Sc. degree from AL-Mansoura University, Faculty of Engineering, Egypt in 1979 and the Ph. D. degree from the 'Ecole National Superior de l'electricit'e et de mechanique de Nancy, INPL, France, in 1986. He is currently an emeritus professor in the Department of Industrial Electronics and Control Engineering, Faculty of Electronic Engineering, Menofia University, Egypt. His research interests include intelligent control systems and chaotic and fractional order systems. 